\title{
Mouth Breathing: A Menace to Developing Dentition
}

\author{
${ }^{1}$ Ankita Jain, ${ }^{2}$ Dara John Bhaskar, ${ }^{3}$ Devanand Gupta, ${ }^{4}$ Priyanka Yadav, ${ }^{5}$ Deepak Ranjan Dalai, ${ }^{6}$ Vikas Jhingala \\ ${ }^{7}$ Yogesh Garg, ${ }^{8}$ Monika Kalra
}

\begin{abstract}
Purpose: To know the adverse effects of mouth breathing on developing dentition.

Introduction: Mouth breathing as an oral habit is seldom discussed in detail and as a consequence has tended to be overlooked by dental professionals. There is a large controversy about the causal relations between dentofacial deformities and mouth breathing habits. A review of current data on the skeletofacial, dental and gingival changes that occur in mouth breathing individuals is given, with the intention of raising the awareness of dental professionals to the special needs of these patients.
\end{abstract}

Materials and methods: This review article is formulated based on the available literature online. A thorough search was made on the pubmed and other reliable sources and then this review is formed.

Conclusion: Some postural and morphological changes during long-term adaptation to oral respiration are evoked: opening of the bite with a lowered postural position of the mandible, reduction of upper arch width, downward and backward rotation of the mandible, increased lower facial height and changes in the inclination of the lower and upper incisors.

Keywords: Mouth breathing, Habit, Dentofacial, Respiration. How to cite this article: Jain A, Bhaskar DJ, Gupta D, Yadav P, Dalai DR, Jhingala V, Garg Y, Kalra M. Mouth Breathing: A Menace to Developing Dentition. J Contemp Dent 2014;4(3):145-151.

Source of support: Nil

Conflict of interest: None

\section{INTRODUCTION}

For some, the saying 'spring is in the air' is quite factual. When the winter snow melts and vegetation bloom, pollen and other materials can inflict chaos on those suffering from seasonal allergies, usually causing a habit

\footnotetext{
${ }^{1,4-8}$ Postgraduate Student, ${ }^{2}$ Professor, ${ }^{3}$ Senior Lecturer

${ }^{1,2,5-8}$ Department of Public Health Dentistry, Teerthanker Mahaveer Dental College and Research Centre, Moradabad Uttar Pradesh, India

${ }^{3}$ Department of Public Health Dentistry, Institute of Dental Sciences, Bareilly, Uttar Pradesh, India

${ }^{4}$ Department of Public Health Dentistry, Rajasthan Dental College and Hospital, Jaipur, Rajasthan, India
}

Corresponding Author: Ankita Jain, Postgraduate Student Department of Public Health Dentistry, Teerthanker Mahaveer Dental College and Research Centre, Moradabad, Uttar Pradesh India, Phone: 09808723156, e-mail: ankitajain.0815@gmail.com called 'mouth breathing'. The mouth does not usually contribute in respiration. For usual dentofacial growth to happen there ought to be normal breathing. Increased struggle to the flow of air through the nasal passages may be considered to be the key reason of mouth breathing. ${ }^{1-4}$

Mouth breathing has been declared to have serious effects on the growth of the facial skeleton and occlusion of teeth on account of the displacement of normal lateral, buccal and lingual muscular forces. ${ }^{5}$ A number of persons may appear to be mouth breathers because of their mandibular posture or incompetent lips. It is common for a 3 to 6-year-old to be slightly lip incompetent. Other children have been labeled mouth breathers because of a suspected nasal airway obstruction. When nose breathing is disrupted by adenoid and tonsil hypertrophy, rhinitis, nasal septum deviation, there is a prevalence of mouth breathing. According to Paul and Nanda, there is much evidence that mouth breathing produces deformities of the jaws, inadequate position or shape of the alveolar process and malocclusion and results in the development of 'adenoidal facies' or 'long face syndrome'.

\section{CLASSIFICATION}

- Sim and Finn (1987) $)^{1,2,8}$ classified mouth breathing as:

- Obstructive: Children with an increased resistance to or a complete obstruction of the normal flow of air through the nasal passages. Seen in ectomorphous individuals with long narrow faces and nasopharyngeal passages.

- Habitual: Child who continually breathes through the mouth by force of habit, although the obstruction has been removed.

- Anatomical: Short upper lip does not permit closure without undue effort.

a. Total blockage: Nasal passages are completely blocked.

b. Partial blockage (Fig. 1).

\section{ETIOLOGY}

Causes of mouth breathing are the following:

- Nasal obstruction ${ }^{1-4}$

- Enlarged turbinate:

This may be due to:

a. Allergies

b. Chronic infections of mucous membrane

c. Atrophic rhinitis 


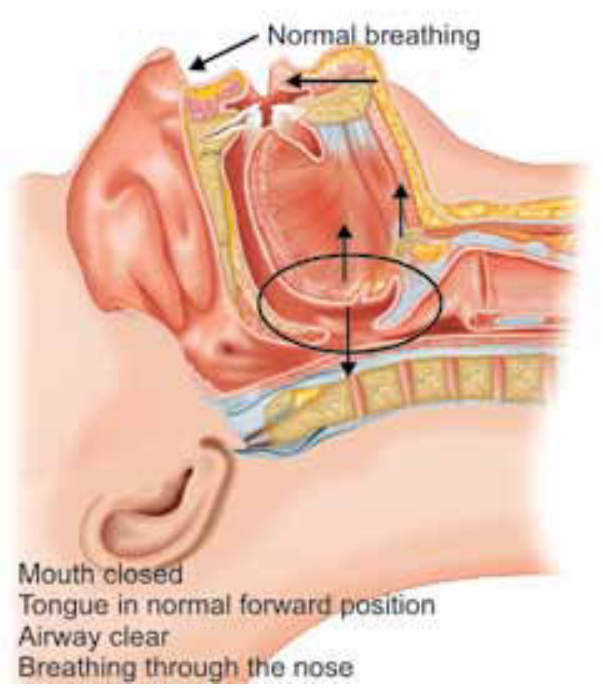

Fig. 1: Difference between normal and obstructed breathing

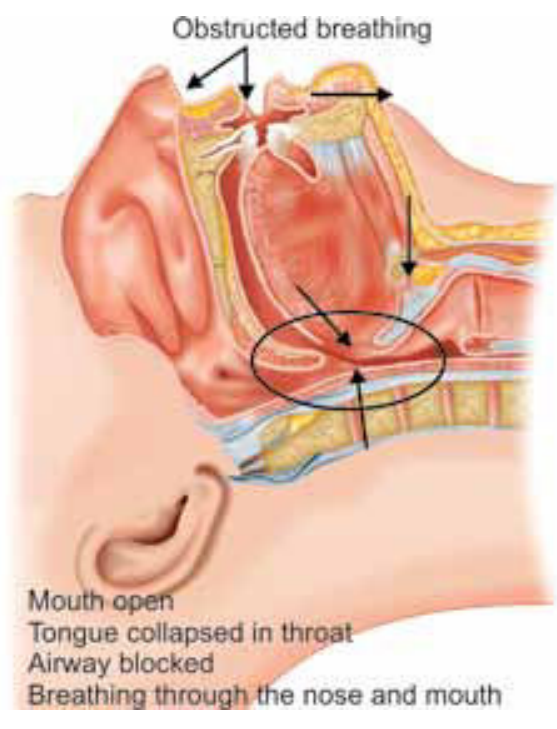

d. Hot and dry climatic conditions

e. Polluted air.

- Hypertrophy of pharyngeal lymphoid tissue (adenoids): Repeated infection results in the overgrowth of lymphoid masses blocks the posterior nares, rendering mouth breathing necessary.

- Intranasal defects:
a. Deviated nasal septum
b. Subluxation of septum
c. Thickness of septum
d. Bony spurs
e Polyps

- Allergic rhinitis

Continuous infections and toxins of the bacteria may sensitize the tissue to develop allergic reactions.

\section{EFFECTS OF MOUTH BREATHING}

Resistance is lacking to the diaphragm and intercoastal muscles so negative pressure is not created to promote airflow. Children who breathe predominantly through their mouth pose difficult problems for healthcare professionals. ${ }^{2,9}$

The head posture is the result of a complex and delicate balance between the muscles involved in the cervical-mandibular-cranial system designed to maintain the pharyngeal airway. Hence, the forward head posture, commonly related to mouth breathing, is described as an adaptation to expand and facilitate the air flow through the oropharynx. ${ }^{10}$

In addition to various types of abnormal facial growth and dental malocclusions, many other medical problems can be attributed to mouth breathing. First and foremost, nasal respiration (which is produced in the nasal sinuses) is essential for the production of nitric oxide. Studies have shown that upper airway obstruction/mouth breathing can cause sleep disorders and sleep apnea. Studies have shown that children with sleep disorders have problems paying attention in school, are often tired, and may exhibit behavior problems; many of these children often are misdiagnosed with attention deficit hyperactivity disor$\operatorname{der}(\mathrm{ADHD}){ }^{11}$

\section{CLINICAL FEATURES}

- Effect on face, ${ }^{1,2}$ (Fig. 2):

1. Lips slack and stay open

2. Short upper lip

3. Molding action of upper lip on incisors is lost thereby resulting in proclination and spacing.

4. Lower lip: heavy and everted.

5. Tongue is suspended between upper and lower arches resulting in constriction of buccal segment (V shape arch).

6. Increased mandibular plane angle.

7. Retrognathic maxilla and mandible.

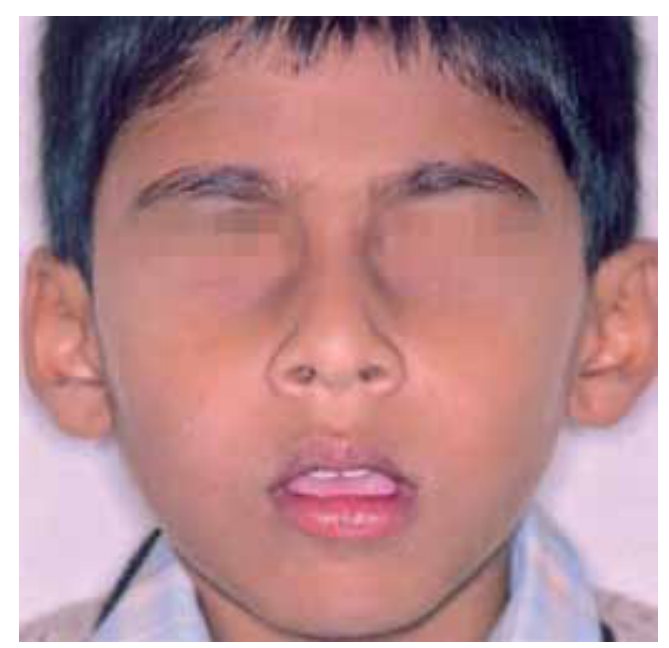

Fig. 2: Adenoid facies 
- Effect on occlusion of teeth ${ }^{1,12}$

1. Proclination of anteriors justified by interposition of the hypertonic lower lip between maxillary and mandibular incisors provoking labioversion of the maxillary incisors. Koski reported that the mandibular incisors presented retroclination in relation to the mandibular plane in patients with hypertrophic adenoid. ${ }^{5}$

2. Distal relation of mandible to maxilla

3. Lower anteriors supraerupt to touch the palatal tissues.

4. Posterior crossbite

5. Anterior open bite $\mathrm{e}^{13,14}$

The maxilla and mandible were more retrognathic in the mouth breathing group. The maxillae were more retrognathic owing to upper airway obstruction resulting from the hypoplasia of the maxillary sinus and narrowing of the nasal cavities. Narrow palatal and cranial widths are also associated. This is due to the low set position of the tongue in order to allow an adequate inflow of air through the mouth. Thus, an imbalance of forces exerted by the tongue and facial musculature on the maxilla leads to a constricted maxillary arch. There may be flaring of incisors and a decrease in the vertical overlap of the anterior teeth 2,3,15-17 (Fig. 3).

- Effect on gingiva ${ }^{1}$ : Gingival tissues: Constant wetting and drying of the gingiva causes irritation, saliva about the exposed gingiva tends to accumulate debris resulting in an increase in bacterial population.

1. Hypertrophic mouth breathing gingivitis

2. Nonhypertrophic mouth breathing gingivitis.

- Speech defects: Abnormalities of the oral and nasal structures can seriously compromise speech performances. Nasal tone in voice is seen. ${ }^{2}$

Effect on lip: These patients frequently have a lip apart posture, although the lip apart posture should not be regarded as pathognomonic for nasal obstruction. On smiling, many of these reveal large amounts of gingiva producing the 'gummy smile'. Children who

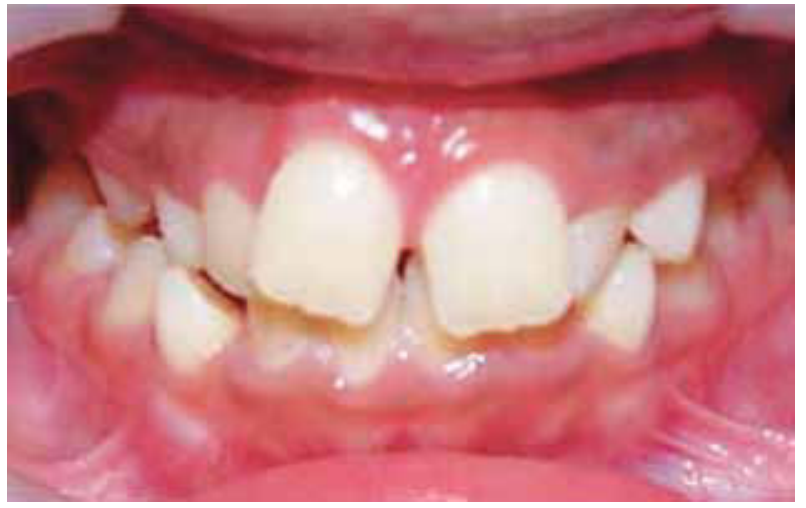

Fig. 3: Effects of mouth breathing on teeth

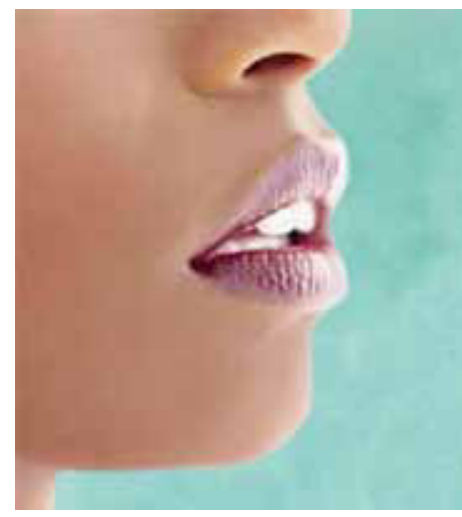

Fig. 4: Lip apart swallow

mouth breathes have a short thick incompetent upper lip and a voluminous curled over lower lip ${ }^{2}$ (Fig. 4).

- Effect on external nares: Long-standing nasal airway obstruction can lead to a disuse atrophy of the lateral cartilage. The result is a slit-like external nares with a narrow nose. ${ }^{2}$

- Other effects: It may lead to otitis media. The palatoglossus muscle is active in the case of nose breathers, whereas the levator palatine activity is lower when nose breathing was compared with mouth breathing. There is also a dull sense of smell and loss of taste. The occurrence of halitosis was high among the children with mouth breathing. Mouth breathing irritates the mucosa, and these children often will have swollen tonsils and adenoids, one of the major causes of upper airway obstruction, sleep disorders and sleep apnea $^{13,15}$ (Fig. 5).

\section{DIAGNOSIS OF MOUTH BREATHING}

Diagnose the habit by looking for the following symptoms:

- Subjective symptoms

1. History: A good history should be recorded from patients and parents also, as children may deny the habit.

2. Clues about nasal stiffness, nasal discharge, sore throat, repeated attacks of cold.

3. Posterior nasal defects.

- Objective symptoms

1. Hoarseness of voice

2. Malocclusion

3. Restlessness at night, feeling thirsty

4. Mouth breathing gingivitis

5. Association with other habits.

- Methods of examination

1. Observe the patient

Mouth breathers: Lips will be apart

Nasal breathes: Lips will be touching

- Ask the patient to take a deep breath through nose. 

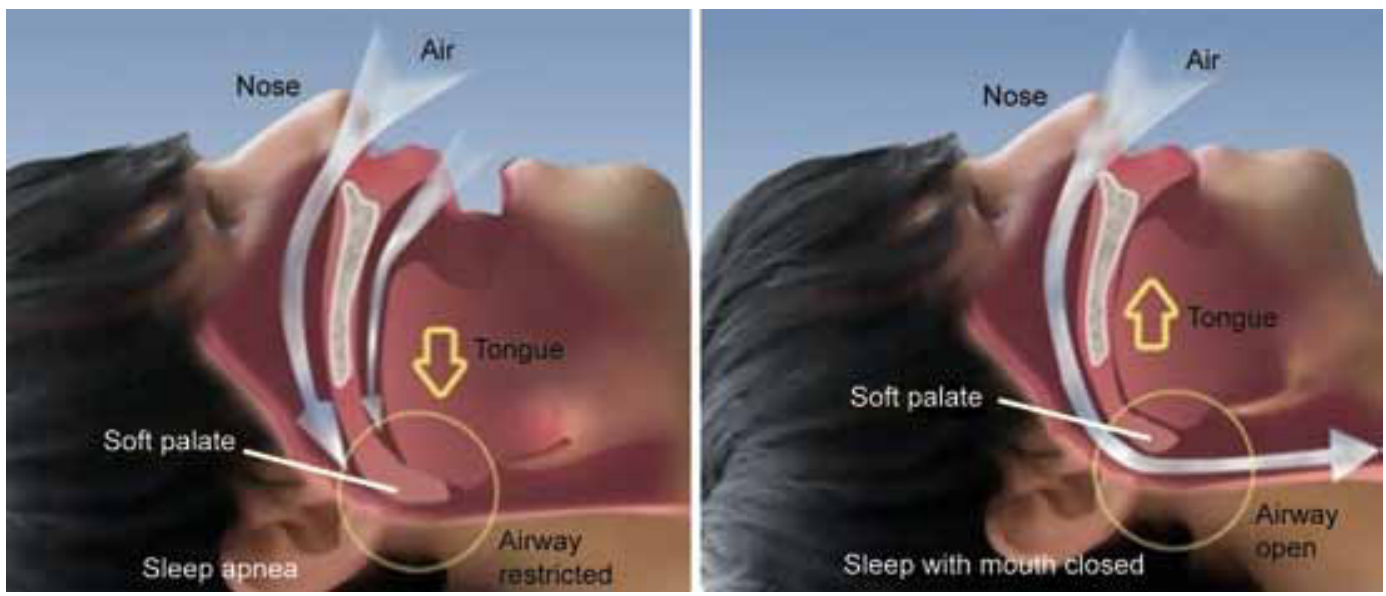

Fig. 5: Sleep apnea

Most mouth breathers respond to this request by inspiring through the mouth. The nose does not change the size or shape of external nares occasionally contracts the nasal orifices while inspiring.

\section{Clinical Tests ${ }^{1,2}$}

- Mirror test: It is also called as Fog test. A double sided mirror is held between the nose and mouth. Fogging on the nasal side of the mirror indicates nasal breathing while fogging on oral side-mouth breathing.

- Massler's water holding test: ${ }^{1,18}$ Patient is asked to hold the mouth full of water. Mouth breathers cannot retain the water for a long time.

- Massler and Zwemer butterfly test/Cotton test: ${ }^{1,18}$ Butterfly shaped cotton strands are placed over the upper lip below nostrils. On exhalation if the fibers of the cotton flutter downwards patient is nasal breather and if fibers flutter upward he is a mouth breather.

- Inductive plethysmography (Rhinometry): ${ }^{1,18}$ The total airflow through the nose and mouth can be quantified using inductive plethysmography, the only reliable way. This allows the percentage of nasal and oral respiration to be calculated. A minority of the long face children had less than $40 \%$ nasal breathing. Nasal air flow characteristics are studied by using devices consisting of flow meters and pressure gauges.

One cross-sectional study used the plethysmograph on normal children and reported:

Prior to age 8-there were as many oral or predominantly oral breathers as nasal or predominantly nasal breathers.

After age 8-the majority of the children were nasal or predominantly nasal breathers (Warren et al, 1990).

Cephalometrics $^{1,2}$ : Can be used to calculate amount of nasopharyngeal space, size of adenoids and to know the skeletal patterns of the patient by taking various cephalometric angles.

\section{TREATMENT CONSIDERATION}

1. Age of child: Mouth breathing in many instances is self correcting after puberty. This can be attributed to the increase in nasal passages as the child grows, thereby relieving the obstruction caused due to enlarged adenoids.

2. ENT examination: An otorhinolaryngologist examination may be advised to determine whether conditions requiring treatment are present in the tonsils, adenoids or nasal septum. If habit continues after removal of cause then it is habitual.

3. Prevention and interception: Mouth breathing can be intercepted by use of an oral screen. ${ }^{1,2}$

\section{TREATMENT OF MOUTH BREATHING}

Treatment according to symptoms: Gingiva of the mouth breathers should be restored to normal health by coating the gingiva with petroleum jelly.

It may be divided under three main factors:

1. Remove the cause: Etiological agents should be treated first. Removal of nasal or pharyngeal obstruction by surgery or local medication should be sought. If a respiratory allergy is present, it should be brought under control.

Rapid maxillary expansion has been reported to reduce the rapid maxillary expansion.

2. Intercept the habit: If the habit continues even after the removal of the obstruction then it should be corrected. Methods of correction:

\section{a. Exercises: ${ }^{1,2,19}$}

- During day time-hold pencil between the lips.

- During night time- - tape the lips together with surgical tape in habitual mouth breathing. 
- Hold a sheet of paper between the lips.

- Piece of card $1 \times 1 \frac{1 / 2 "}{1}$ held between the lips.

- Patients with short hypotonic upper lip: Stretch the upper lip to maintain lip seal or stretch in downward direction toward the chin.

- Button pull exercise: A button of 11/2" diameter is taken and a thread is passed through the button hold. The patient is asked to place the button behind the lip and pull the thread, while restricting it from being pulled out by using lip pressure.

- Tug of war exercise: This involves two buttons, with one placed behind the lips while the other button is held by another person to pull the thread. Blow under the upper lip and hold under tension to a slow count of 4 repeat 25 times a day. Draw upper lip over the upper incisors and hold under tension for a count of 10 .

b. Maxillothorax myotherapy: ${ }^{1,2}$ This was advocated by Macaray 1960. These expanding exercises are used in conjunction with the Macaray activator. Macaray constructed an activator out of aluminum with which development of the dental arches and dental base relationship could be corrected at the same time as encouraging mouth breathing. The mouth breather holds the activator in the mouth and at the same time with the left and right arms alternately carries out 10 exercises 3 times a day.

c. Oral screen ${ }^{1-3,20-22}$

- First introduced by Newell in 1912.

- It is a myofunctional appliance that is easy to fabricate and easy to wear.

\section{DEFINITION}

- Graber: $:^{22}$ An appliance that utilizes the musculature to control abnormal muscle habits and aids in correction of the developing malocclusion.

- C Phillip Adams: $:^{12}$ A removable appliance, used to deflect or eliminate muscle forces on certain teeth. Commonly placed in the vestibule between the lips, cheeks and the teeth.

\section{PRINCIPLE}

It is a functional appliance by virtue of the fact that it produces its effects redirecting the pressures of the muscular and soft-tissue curtain of the cheeks and lips. It works on the principle of both force application and force elimination. For example anterior teeth proclination can be corrected utilizing the principle of force application. The screen comes in contact with the proclined teeth so that the forces from the lips are transmitted directly to the proclined teeth through the screen. Posterior cross bite can be corrected utilizing the principle of force elimination by providing a spacer between the teeth and the screen. ${ }^{20,21}$

\section{INDICATIONS}

1. Habit-correcting appliance

2. It helps retrain and strengthen lip action

3. Lip exercises are possible with oral screen, which improves the tonicity of the lips.

4. To correct simple labioversion of the maxillary anterior teeth.

\section{CONTRAINDICATION}

It should not be used if the child has nasorespiratory distress or a nasal obstruction. ${ }^{22}$

\section{CONSTRUCTION ${ }^{12,20,21}$}

Upper and lower impressions are made must reproduce the full depth of the labial sulcus and casts are prepared. The casts are occluded and sealed. Posteriorly, the appliance will extend up to the distal margin of the last erupted teeth. The upper and lower borders will extend to the full depth of the sulcus.

Rapid maxillary expansion (RME): ${ }^{1,23,24}$ Patients with narrow, constricted maxillary arches benefit from RME procedures aimed at widening of the arch. It increases nasal air flow and decrease nasal air resistance. Increase in intranasal space occurs due to outer walls of nasal cavity moving apart.

3. Correction of malocclusion ${ }^{1,2,25-30}$

a. Children with class I skeletal and dental occlusion and anterior spacing-oral shield appliance

b. Class II division 1 without crowding, age 5 to 9 years, monobloc activator both to correct malocclusion and deterrence of habit.

c. Class III malocclusion: interceptive methods are recommended as chin cap.

\section{DISCUSSION}

Mouth breathing habit was the second most prevalent habit in the study conducted by Deepak P Bhayya and Tarulatha R Shyagali ${ }^{31}$ with the incidence rate of $17 \%$. This incidence was higher when compared to the findings of the previous studies. Amr Abou-EI-Ezz et al, in their study on prevalence of mouth breathing habit and its probability as etiological factor of malocclusion have concluded that malocclusion is highly associated with habits existence and this relationship is statistically highly significant $(\mathrm{p}<0.001)$. Motta $\mathrm{L}^{17}$ finds out that 
there were a significantly greater number of boys with the mouth breathing pattern than girls.

Malhotra $S$ et $a 1^{18}$ finds out that children who breathe predominantly through their mouth pose difficult problems for healthcare professionals. The dental professional apprehend that faces of the mouth breathers might develop aberrantly, possibly because of disruption of normal functional relationships caused by chronic airway obstruction and altered path of airway. Oral respiration, low tongue posture and elongation of lower anterior facial height are apparent at 3 years of age but more commonly detected after age five. The deleterious impact of decreased nasorespiratory function is virtually complete by puberty. In their study, an increase in gonial angle in mouth breathers was found and which was statistically significant. Bresolin et $\mathrm{a}^{15}$ and results of Ung et $\mathrm{a}^{19}$ confirms the finding of their study. According to Corruccini et al, ${ }_{1}^{14}$ crossbite is prevalent in mouth breathers which are in agreement with Bresolin et al. ${ }^{15}$ This conclusion should be treated with some caution, as the difference was statistically significant only in the rural sample where mouth breathing was infrequent.

There is some evidence that OS (oral screen) effects on incisor position may be due to only mechanical pressure on the upper incisors (Knosel M et $\mathrm{al}^{20}$ and Owman-Moll and Ingervall). ${ }^{21}$ However in many cases, assumed to be induced by hypotonic mimic muscles and stopped by subsequent open mouth situations, implicating lownegative intraoral pressure at the level of environmental atmospheric pressure, it may be postulated that orthodontic strategies should also address the normalization of these factors.

\section{CONCLUSION}

Many habits may be considered normal for a certain stage of the child's development. If parents are aware of normal and can differentiate between normal and abnormal for that age group, and have clear mind set regarding the cause and effect of particular habit, the situation can be dealt in better way. If the habit is causing a malocclusion or other pathologic process, it is the privilege and responsibility of the dentist to work with the child and parent's toward a resolution of the problem. So that dental care can be provided to the child timely. Habit can be intercepted before child needs to undergo corrective treatment.

\section{REFERENCES}

1. Singh G. Textbook of Orthodontics. 2nd ed. Chapter 49-oral habits and their management, p. 581-612.

2. Tandon S. Textbook of Pedodontics. 2nd ed. Chapter 39: Commonly Occurring Oral Habits in Children and their Management, p. 492-526.
3. Faria PTM, Ruellas AC, Matsumoto MA, Lima WA, Pereira FC. Dentofacial morphology of mouth breathing children. Braz Dent J 2002;13(2):129-132.

4. Mouth breathing can cause major health problems. PHYSorg. com 6 Apr, 2010.

5. Paul JL, Nanda RS. Effect of mouth breathing on dental occlusion. Angle Orthod 1973;43(2):201-206.

6. Stokes N, Della MD. A student research review of the mouth breathing habit: discussing measurement methods, manifestations and treatment of the mouth breathing habit. Probe 1996;30(6):212-214.

7. Pinkham, Christensen JR, Fields HW Jr, Adair SM. Pediatric Dentistry-Infancy through adolescence. Oral habits Ch. 26. 4th ed. p. 431-439.

8. Finn, Sim JM, Finn SB. Clinical Pedodontics oral habits in children Ch. 17. 4th ed. p. 370-385.

9. Curran K, Yuan P, Coyle D. Using acoustic sensors to discriminate between nasal and mouth breathing. Int J Bioinfor Res Applic 2012;7(4):10-32.

10. Bolzan GP, Souza JA, Boton LM, Silva AMT, Corrêa ECR. Facial type and head posture of nasal and mouth-breathing children. J Soc Bras Fonoaudiol 2011;23(4):315-320.

11. Jefferson Y. Mouth breathing: adverse effects on facial growth, health, academics, and behavior. General Dentistry 2010;58(1):18-25.

12. Adams CP, Kerr WJS. The design, construction and use of removable orthodontic appliances.

13. Limme M. Orthognathic and orthodontic consequences of mouth breathing. Acta Otorhinolaryngol Belg 1993;47(2): 145-155.

14. Corruccini RS, Flander LB, Kaul SS. Mouth breathing, occlusion and modernization in a North Indian population. Angle Orthod 1985;55(3):190-196.

15. Bresolin D, Shapiro PA, Shapiro GG, Chapko MK, Dassel $\mathrm{S}$. Mouth breathing in allergic children: its relationship to dentofacial development. Am J Orthod 1983;83(4):334-340.

16. Patrick M, John M. Craniofacial changes and mouth breathing. Irish Dental J 2011;57(3):12-18.

17. Motta LJ, Bachiega JC, Guedes CC, Laranja LT, Bussadori SK. Association between halitosis and mouth breathing in children. Clinics (Sao Paulo) 2011;66(6):939-942.

18. Malhotra S, Pandey RK, Nagar A, Agarwal SP, Gupta VK. The effect of mouth breathing on dentofacial morphology of growing child. J Indian Soc Pedod Prev Dent 2012;30(1): 27-31.

19. Thuer U, Ingervall B. Effect of muscle exercise with an oral screen on lip function. Eur J Orthod 1990;12(2):198-208.

20. Knosel M, Jung K, Kinzinger G, Bauss O, Engelke W. A controlled evaluation of oral screen effects on intraoral pressure curve characteristics. European J Orthod 2010;32(5):535-541.

21. Owman-Moll P, Ingervall B. Effect of oral screen treatment on dentition, lip morphology, and function in children with incompetent lip. Am J Orthod 1984;85(1):37-46.

22. Graber TM, Rakosi T, Petrovic AG. Dentofacial orthopedics with functional appliances 1985;p. 496-519.

23. Arvind K, Deepa G, Muruganandham, Shivangi S. Rapid maxillary expansion: a unique treatment modality in dentistry. J Clin Diag Res 2011;5(4):906-911.

24. Gurel HG, Memili B, Erkan M, Sukurica Y. Long-term effects of rapid maxillary expansion followed by fixed appliances. Angle Orthod 2010;80(1):5-9. 
25. Bloch KE, Iseli A, Zhang JN, Xie X, Kaplan V, Stoeckli PW, Russi EW. A randomized, controlled crossover trial of two oral appliances for sleep apnea treatment. Am J Respir Crit Care Med 2000;162(1):246-251.

26. Jain A, Bhaskar DJ, Gupta DA. Adverse oral habits: potential harm to dentition. Lap Lambert Academic Publishing, 2013.

27. Cozza P, Polimeni A, Ballanti F. A modified monobloc for the treatment of obstructive apnoea in paediatric patients. Eur J Orthod 2004;26(5):523-530.
28. Hisano M, Ohtsubo K, Chung CJ, Nastion F, Soma K. Vertical control by combining a monoblock appliance in adult class III overclosure treatment. Angle Orthod 2006;76(2):226-235.

29. Singh S. Deleterious oral habits. Indian J Dent Sc 2009;1(2):15-20.

30. Jain A, Bhaskar DJ, Yadav P, Lukram A, Khurana R. Bruxism: an obscure pain. Int J Dent Med Res 2014;1(1):21-30.

31. Bhayya DP, Shyagali TR. Prevalence of oral habits in 11-13 year-old school children in Gulbarga city, India. Virtual J Orthod 2009;8(3):1-4. 